\title{
Endoscopic full-thickness resection using an over-the-scope device for treatment of recurrent / residual colorectal neoplasia: a single-center case series
}

\author{
Annabell von Helden ${ }^{1}$, Ralf Hildenbrand ${ }^{2}$, Bernd Sido ${ }^{3}$ and Franz Ludwig Dumoulin ${ }^{1 *}$ (1)
}

\begin{abstract}
Background: Endoscopic mucosal resection (EMR) in piecemeal technique is the treatment standard for larger flat or sessile colorectal lesions. The method is burdened by a high recurrence rate mostly presenting as difficult to resect lesions. In these situations, endoscopic full thickness resection (EFTR) with an over-the-scope device offers the option of complete resection despite scar formation.

Methods: We conducted a retrospective case review of 30 consecutive EFTR interventions on small ( $<20 \mathrm{~mm}$ ), difficult to resect recurrent / residual colorectal neoplastic lesions treated by EFTR.

Results: EFTR was technically feasible in 28/30 (93,3\%) of the cases with an R0 resection in 24/30 (80\%) and a median procedure time (marking to full thickness resection) of 34,5 min (11-120). After the first 15 procedures, the per-protocol rate increased from $13 / 15$ to $15 / 15$ and the R0 resection rate increased from 9/15 (69,2\%) to 15/15 $(100,0 \% ; p<0.01)$. One patient suffered from a delayed perforation the day after the procedure and needed emergency surgery $(3,6 \%)$. Minor bleeding occurred in $3 / 28$ patients $(10,7 \%)$ and post-interventional fever in one patient (3,6\%). The 30-day mortality rate was $0 \%$.

Conclusions: EFTR with an over-the-scope device is a useful method for endoscopic resection of difficult to treat recurrent or residual colorectal neoplasia after previous endoscopic therapy. High RO resection rates were observed after a relatively short learning curve. The complication rate in this series seems acceptable given the complexity of the resected lesions.
\end{abstract}

Keywords: Colorectal neoplasia, Endoscopic full thickness resection, Adenoma recurrence, Fibrosis, Perforation, Bleeding

\section{Background}

Polypectomy and endoscopic mucosal resection (EMR) either en bloc or in piecemeal fashion - are established treatment standards for colorectal neoplasia such as adenoma or low risk early cancer [1-3]. Problems arise in cases of incomplete resections after fragmented (so called 'piecemeal') mucosectomy with reported recurrence rates of $20-30 \%[4,5]$. In fact, incomplete polypectomy

\footnotetext{
* Correspondence: f.dumoulin@gk-bonn.de

${ }^{1}$ Department of Medicine and Gastroenterology, Gemeinschaftskrankenhaus Bonn, Academic Teaching Hospital, University of Bonn, Bonner Talweg 4-6, 53113 Bonn, Germany

Full list of author information is available at the end of the article
}

probably has a relevant impact on interval cancers [6]. While recurrences after previous endoscopic therapy are usually small, their treatment is difficult due to scar formation. Even endoscopic submucosal dissection (ESD) favored by Japanese guidelines [7] - does not reliably result in $\mathrm{R} 0$ resections in cases of severe fibrosis $[8,9]$.

Recently, an endoscopic full-thickness resection (EFTR) device (FTRD ${ }^{\circ}$, Ovesco, Germany) has been developed. The device combines a large over-the-scopeclip (OTSC) to create a full thickness plication with a snare, which is subsequently used to cut the full thickness specimen $[10,11]$. The method has been applied for the treatment of colorectal non-lifting lesions, lesions 
in anatomically difficult localization and also for smaller subepithelial tumors in several case series and one large prospective multicenter study [12-19]. In this study, we have focused on the clinically important aspect of endoscopic treatment for difficult to resect colorectal neoplasia after previous endoscopic therapy.

\section{Methods}

\section{Patients and lesions}

Between 01/2016 and 11/2018 we performed 30 endoscopic full thickness resections using the FTRD ${ }^{\circ}$ device (Ovesco, Tübingen, Germany) in 29 consecutive patients (19 male / 10 female; median age 72,7 years / range 21,5-81,6; Table 1). All lesions were $<20 \mathrm{~mm}$ in size and were judged difficult to resect because of non-lifting due to scar formation after previous endoscopic resection. Localization of the lesions was in the right colon $(n=18)$, left colon $(n=9)$ and rectum $(n=3)$. The procedure time was measured from the initial marking of the lesion until the final endoscopic control of the clip closure. All procedures were performed by a single endoscopist (F.L.D.) who had received team training with the FTRD ${ }^{\circ}$ device on isolated pig colon provided by the manufacturer. Informed consent for the procedure was obtained from all patients. Data on endoscopic procedures were prospectively recorded (Clinic WinData, E\&L, Erlangen, Germany). Retrospective analysis was done by review of the digital patient charts. The study conforms to the provisions of the Declaration of Helsinki. It was approved by institutional board review of the Gemeinschaftskrankenhaus Bonn and - in accordance with federal regulations ( $\mathbb{1} 15$ of the professional code / 'Berufsordnung für die nordrheinischen Ärztinnen und Ärzte') - specific consent to participate in this retrospective case series was waived.

Table 1 Patients and lesions

\begin{tabular}{|c|c|}
\hline \multicolumn{2}{|l|}{ Patients $(n=29)$ and lesions $(n=30)$} \\
\hline Age, years (median / range) & $72,7(21,5-81,6)$ \\
\hline Gender (female / male) & $10 / 19$ \\
\hline \multicolumn{2}{|l|}{ Localization (n) } \\
\hline - right colon (ascending / transverse) & 18 \\
\hline - left colon (descending / sigmoid) & 9 \\
\hline - rectum & 3 \\
\hline \multicolumn{2}{|l|}{ Pre treatment histology $(n)$} \\
\hline - serrated adenoma & 2 \\
\hline - tubular or tubular-villous adenoma; low grade IEN & 16 \\
\hline - tubular or tubular-villous adenoma; high grade IEN & 8 \\
\hline - carcinoma & 4 \\
\hline $\begin{array}{l}\text { Procedure time, marking to final control (median / } \\
\text { range) }\end{array}$ & $34,5(11-120 \mathrm{~min})$ \\
\hline $\begin{array}{l}\text { Size of resected specimen, max. diameter (median / } \\
\text { range) }\end{array}$ & $25(14-33 \mathrm{~mm})$ \\
\hline
\end{tabular}

\section{EFTR procedure with the FTRD device}

EFTR was carried out under conscious sedation with propofol, fentanyl and prophylactic single shot antibiosis (cefuroxime). After endoscopic evaluation and marking of the lesion (Fig. 1a, b), the FTRD ${ }^{\circ}$ system was mounted and the endoscope re-advanced to the lesion. Full thickness resection with the integrated snare was accomplished after pulling the tissue into the cap and release of the clip (Fig. 1c, d). The settings of the Erbe Vio 3 electrosurgical unit (Erbe Elektromedizin, Tübingen, Germany) were forced coagulation 1.0 for initial marking of the target lesion and endocut Q 1.0 for cutting the lesion. After retrieval of the specimen and removal of the FTRD $^{\circ}$ system a repeat endoscopy was performed to control the positioning of the clip (Fig. 1e) and to rule out any possible injury that might have happened during the passage of the FTRD ${ }^{\circ}$ device to the target lesion.

\section{Histopathology}

The specimens were gently stretched and then fixed on corkboard. Histopathology was performed with specific attention to the resection margins to confirm a complete resection (Fig. 1f). Patients with early cancer were presented in the interdisciplinary tumor board.

\section{Post-procedural care}

Patients had a liquid diet for the first $6 \mathrm{~h}$ after the procedure and were allowed to consume a soft diet the day after. We performed clinical visits and laboratory controls on the evening after the procedure as well as on the first post-interventional days and in any case of suspected adverse events. The majority of patients could be discharged on the second post-interventional day. We recommended follow up endoscopies in accordance with the current German S3 guideline [3].

\section{Definition of outcome and complications}

We defined 'technical feasibility' as reaching the target lesion and 'R0 resection' if both vertical and lateral margins were free of adenoma or cancer. A 'perforation' was diagnosed if a complete transmural lesion was identified during the procedure or if clinical and radiological signs of perforation were demonstrated after the procedure. A 'major bleeding' was defined as a loss of $\geq 3$ hemoglobin units with signs of gastrointestinal bleeding after the completion of the intervention.

\section{Statistics}

Group comparisons were done with Fisher's exact test for categorical (https://www.socscistatistics.com) and students t-test (Microsoft Excel for Mac 2011) for continuous variables. 

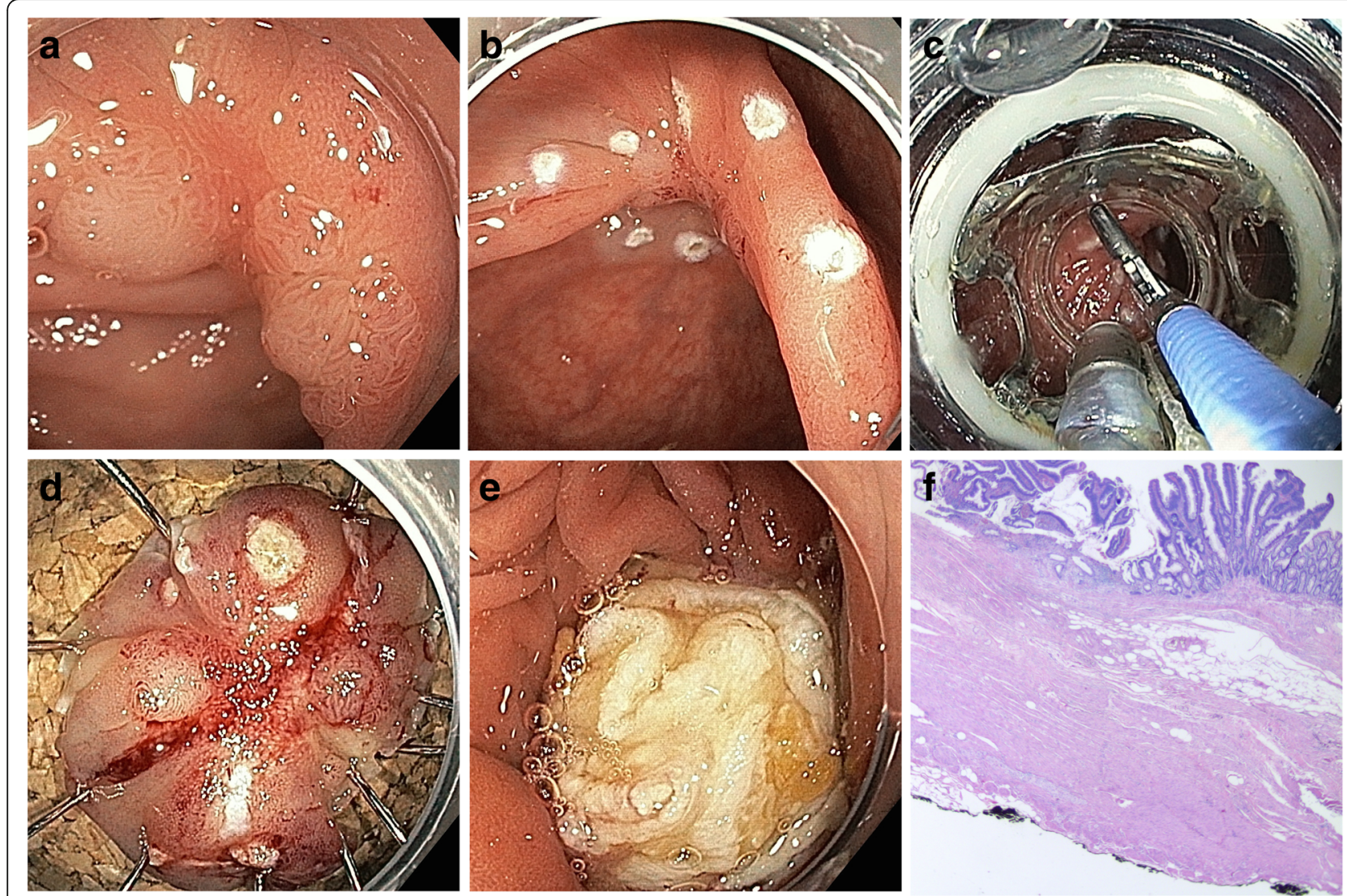

Fig. 1 Endoscopic full thickness resection with the FTRD ${ }^{\circledR}$ device. a Residual adenoma after previous piecemeal EMR; note the central scar. $\mathbf{b}$ Marking of the lesion. c Retraction of the lesion into the FTRD cap. $\mathbf{d}$ Resected specimen pinned on corkboard. e Resection site with FTRD clip in situ. $\mathbf{f}$ Histopathology showing full thickness resection of adenoma

\section{Results}

\section{Efficacy}

EFTR was technically feasible in $28 / 30$ patients $(93,3 \%)$ with a median procedure time (marking to full thickness resection) of $34,5 \mathrm{~min}$ (range 11-120). In two patients the FTRD device could not be advanced to the lesion due to sigmoid (inflammatory) strictures. Both full thickness and R0 resection rates were of $80 \%(24 / 30)$ on intent to treat analysis and $85,7 \%(24 / 28)$ on per protocol analysis (Fig. 2, Table 2).

In four EFTR interventions we could not achieve R0 resection. The endoscopic resection was judged complete in two of them, but histology showed positive resection margins. Follow up has been done for one patient and did not show residual neoplasia. In two other patients we had experienced difficulties in mobilizing the colonic wall into the resection cap due to fibrosis. The resection was diagnosed as incomplete at the final endoscopic control of the resection area. One patient had additional surgery due to high grade intraepithelial neoplasia; follow up data are not available for the other (Fig. 2).

The final histology showed advanced lesions in 12 patients including four carcinomas that had been diagnosed beforehand for possible curative treatment (Table 3). Two of these were evaluated as low risk lesions and - according to the German S3 guideline [3] - the patients were left without additional surgery. The two other lesions had been classified as potentially deep submucosal invasive according to the NICE classification [20] and the patients had been informed about the possibility of a non-curative resection. Histopathology showed pT2, G2, Pn0, L0, V0 R0 in both cases and surgery was recommended. No lymph node metastasis was found after surgical resection in one patient; the other refused additional treatment and is without recurrence or metastasis after 14 months of follow-up.

Endoscopic follow-up data are available for 12 patients with one adenoma recurrence despite previous R0 EFTR resection after intial piecemeal EMR of a large rectal lesion (Fig. 2).

\section{Complications}

We observed one major complication, a delayed perforation the day after EFTR necessitating emergency surgery. In addition, three patients reported minor, selflimiting hematochezia and one patient developed fever 


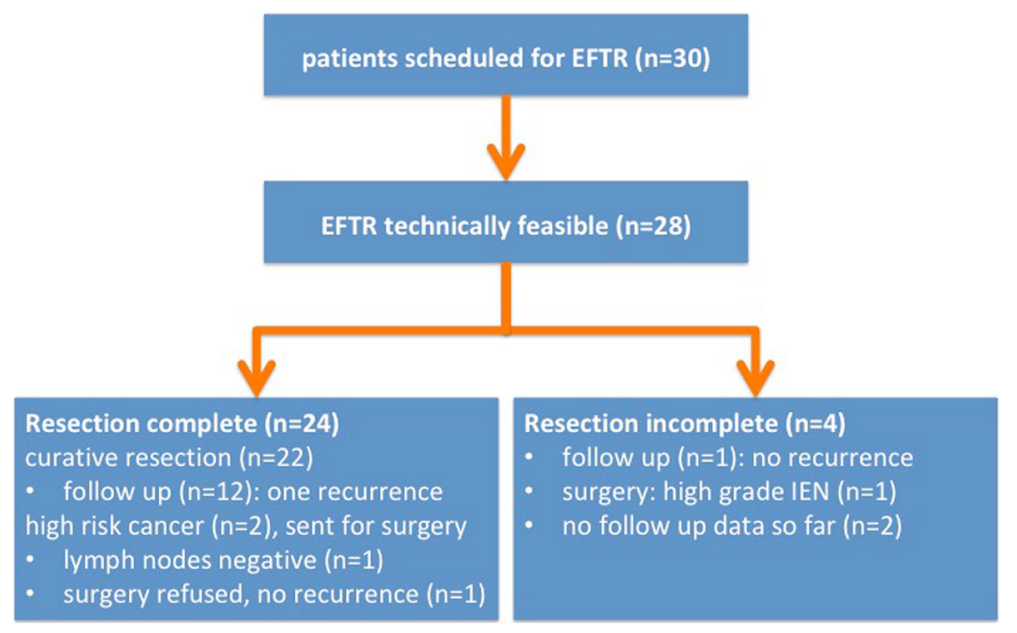

Fig. 2 Outcome in 30 EFTR procedures. Flowchart with clinical outcome in 30 EFTR procedures

without abdominal pain after EFTR. The 30-day mortality rate was $0 \%$ (Table 2 ).

\section{Learning curve}

When analyzing the efficacy and complication rates of EFTR procedures a significant increase in R0 resection rate was observed after the first 15 procedures $(9 / 15$ vs. $15 / 15 ; p<0.01)$. Procedure times were not significantly decreased: median $36 \mathrm{~min}$ (range 21-120) versus $31 \mathrm{~min}$ (range 11-69). Of note, the two cases where the FTRD device could not be advanced to the lesion were among the first 15 procedures.

\section{Discussion}

To date, there are limited data on endoscopic full thickness resection with the FTRD device including one large prospective study treating both epithelial and subepithelial lesions [15-19]. While these studies mainly concentrated on technical aspects, including EFTR for different indications, this study focused on EFTR procedures with the FTRD device in patients with difficult to treat, non-lifting residual / recurrent neoplasia after previous endoscopic

Table 2 Outcome of 30 EFTR procedures

\begin{tabular}{llll}
\hline & Number & $\begin{array}{l}\text { Intent to treat } \\
(n=30)\end{array}$ & $\begin{array}{l}\text { Per protocol } \\
(n=28)\end{array}$ \\
\hline Full thickness resection & 24 & $80,0 \%$ & $85,7 \%$ \\
R0 resection & 24 & $80,0 \%$ & $85,7 \%$ \\
$\begin{array}{l}\text { Complications } \\
\text { • perforation }\end{array}$ & 1 & $3,3 \%$ & \\
• minor bleeding & 3 & $10,0 \%$ & $3,6 \%$ \\
• fever after EFTR & 1 & $3,3 \%$ & $10,7 \%$ \\
• emergency surgery & 1 & $3,3 \%$ & $3,6 \%$ \\
• 30-day mortality & 0 & $0,0 \%$ & $3,6 \%$ \\
\hline
\end{tabular}

resection. Indeed, this is a very common problem, giving the fact that fractionated mucosectomy is the standard treatment for larger flat or sessile colorectal neoplasia in western countries. We observed two treatment failures, were the device could not be advanced to the target lesion. For the remaining 28 procedures the $\mathrm{R} 0$ resection rate was $85,7 \%$. A relatively quick learning curve was observed for the R0 resection rate, which increased from $9 / 15$ to $15 / 15$. Emergency surgery was needed in one patient when perforation developed the day after the procedure.

The efficacy data presented here are comparable to data from the largest prospective study with the FTRD device published [15] and two other smaller case series $[16,17,19]$ (Table 4). They are also comparable to results of ESD in these particular situations [7]. However, compared to other advanced endoscopic resection techniques such as ESD [21], the method has a quick learning curve, which lead to an R0 resection of $100 \%$ after having performed the first 15 cases.

The specific advantage of full thickness resection became obvious in the case of the two high-risk cancers. In fact, these lesions were already pT2 cancers with initial infiltration of the proper muscle layer. In this situation EMR or ESD might have resulted in perforation and potential translocation of cancerous tissue - which

Table 3 Final histology of 28 resected specimens

\begin{tabular}{lll}
\hline & Number & Percentage \\
\hline $\begin{array}{l}\text { Serrated adenoma } \\
\begin{array}{l}\text { Tubular or tubular villous adenoma, } \\
\text { low-grade IEN }\end{array}\end{array}$ & 2 & $7,1 \%$ \\
$\begin{array}{l}\text { Tubular or tubular villous adenoma, } \\
\text { high-grade IEN }\end{array}$ & 8 & $50 \%$ \\
Carcinoma, low-risk & 2 & $28,6 \%$ \\
Carcinoma, high-risk & 2 & $7,1 \%$ \\
\hline
\end{tabular}


Table 4 Outcome of studies using the FTRD device

\begin{tabular}{|c|c|c|c|c|c|c|}
\hline Study, year & (n) & Lesions (n) & Technical feasibility & Full thickness & Ro & Emergency surgery \\
\hline Richter-Schrag, 2016 [17] & 20 & $\begin{array}{l}\text { recurrence (9) } \\
\text { non-lifting (3) } \\
\text { T1 Carcinoma (6) } \\
\text { NET (2) }\end{array}$ & $75 \%$ & $80 \%$ & $80 \%$ & $5 \%$ \\
\hline Schmidt, 2018 [15] & 181 & $\begin{array}{l}\text { recurrence (72) } \\
\text { non-lifting (32) } \\
\text { T1 Carcinoma (15) } \\
\text { SET (23) } \\
\text { difficult location }\end{array}$ & $89,5 \%$ & $76,9 \%$ & $76,9 \%$ & $2,2 \%$ \\
\hline Valli, 2018 [18] & 60 & 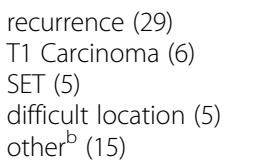 & $88 \%$ & $88,8 \%$ & $79 \%$ & $2,0 \%$ \\
\hline Vitali, 2018 [16] & 13 & $\begin{array}{l}\text { recurrence (4) } \\
\text { non-lifting (7) } \\
\text { NET (1) } \\
\text { difficult location (1) }\end{array}$ & $100 \%$ & n.a. & $83,3 \%$ & $0,0 \%$ \\
\hline Andrisani, 2019 [19] & 110 & $\begin{array}{l}\text { recurrence (65) } \\
\text { non-lifting (12) } \\
\text { T1 Carcinoma (16) } \\
\text { SET (10) } \\
\text { difficult location (4) } \\
\text { other (3) }\end{array}$ & $94,4 \%$ & $91,0 \%$ & $92 \%$ & n.a. \\
\hline This study & 30 & recurrence (30) & $93,3 \%$ & $\begin{array}{l}80,0 \% / \\
85,7 \%\end{array}$ & $80,0 \% / 85,7 \%$ & $\begin{array}{l}3,3 \% / \\
3,6 \%^{c}\end{array}$ \\
\hline
\end{tabular}

Difficult location: e.g. at the appendix or a diverticulum

${ }^{b}$ Other: e.g. in addition to piecemeal resection; after resection of malignant polyp

${ }^{\mathrm{C}}$ Data for R0 resection and emergency surgery given as intent to treat / per protocol, respectively.

was avoided by full thickness R0 resection. On the other hand it must be emphasized, that even $\mathrm{R} 0$ resection of a recurrence does not rule out further recurrence at the same resection site. Thus, one patient developed a second recurrence despite initial $\mathrm{R} 0$ resection of a first recurrence. It is therefore mandatory to encourage timely endoscopic follow up - even after R0 resection of a recurrent adenoma - in particular if recurrence occurs after fragmented resection of a very large adenoma.

The rate of emergency surgery reported here is relatively high compared to other EFTR studies [14-16, 18] or to studies on EMR or ESD $[1,3,7]$. We think this is due to the fact that the study included only a relatively small number of cases. Moreover, no perforation occurred after the first 15 interventions. Finally, it must be pointed out, that EFTR was performed on lesions that otherwise would have been treated either by coagulation (i.e. no control over completeness of eradication) or sent for laparoscopic surgery.

\section{Conclusion}

In conclusion, EFTR with the FTRD device is a useful tool for smaller sized difficult-to-resect colorectal neoplasia e.g. after previous piecemeal resection. After a short learning curve high $\mathrm{R} 0$ resection rates are observed. The rate of emergency surgery is substantial but seems acceptable given the complexity of the resected lesions.

\begin{abstract}
Abbreviations
EFTR: Endoscopic full thickness resection; EMR: Endoscopic mucosal resection; ESD: Endoscopic submucosal dissection; FTRD: Full thickness resection device; G: Grading; IEN: Intraepithelial neoplasia; L: Lymphatic infiltration; n.a.: not available; NET: Neuroendocrine tumor; Pn: Perineural infiltration; pT: primary tumor; R: Resection status; SET: Subepithelial tumor; sm: submucosal; V: Vessel infiltration
\end{abstract}

\section{Acknowledgements}

Not applicable.

\section{Authors' contributions}

$\mathrm{AvH}$ and FLD: conception / design of study, data acquisition / analysis / interpretation, draft of manuscript; $\mathrm{RH}$ : data acquisition / analysis / interpretation; BS: data analysis / interpretation. All authors have approved the submitted version and have agreed to be personally accountable for the author's own contributions.

\section{Funding}

No funding received for the presented study.

Availability of data and materials

The datasets used and/or analysed during the current study are available from the corresponding author on reasonable request.

Ethics approval and consent to participate

The study has been performed in accordance with the Declaration of Helsinki and has been approved by Institutional Board Review of the Gemeinschaftskrankenhaus Bonn.

Consent for publication

Not applicable. 


\section{Competing interests}

The authors declare that they have no competing interests.

\section{Author details}

'Department of Medicine and Gastroenterology, Gemeinschaftskrankenhaus Bonn, Academic Teaching Hospital, University of Bonn, Bonner Talweg 4-6, 53113 Bonn, Germany. ${ }^{2}$ Institute for Pathology Bonn-Duisdorf, Heilsbachstr. 15, 53123 Bonn, Germany. ${ }^{3}$ Department of General and Abdominal Surgery, Gemeinschaftskrankenhaus Bonn, Academic Teaching Hospital, University of Bonn, Bonner Talweg 4-6, 53113 Bonn, Germany.

Received: 17 February 2019 Accepted: 3 July 2019

Published online: 10 July 2019

\section{References}

1. Ferlitsch M, Moss A, Hassan C, Bhandari P, Dumonceau JM, Paspatis G, et al, Colorectal polypectomy and endoscopic mucosal resection (EMR): European Society of Gastrointestinal Endoscopy (ESGE) clinical guideline. Endoscopy. 2017:49(3):270-97.

2. Hwang JH, Konda V, Abu Dayyeh BK, Chauhan SS, Enestvedt BK, Fujii-Lau LL, et al. Endoscopic mucosal resection. Gastrointest Endosc. 2015;82(2):215-26.

3. Schmiegel W, Buchberger B, Follmann M, Graeven U, Heinemann V, Langer T, et al. S3-Leitlinie - Kolorektales Karzinom. Zeitschrift fur Gastroenterologie. 2017:55(12):1344-498.

4. Belderbos TD, Leenders M, Moons LM, Siersema PD. Local recurrence after endoscopic mucosal resection of nonpedunculated colorectal lesions: systematic review and meta-analysis. Endoscopy. 2014;46(5):388-402.

5. Knabe M, Pohl J, Gerges C, Ell C, Neuhaus H, Schumacher B. Standardized long-term follow-up after endoscopic resection of large, nonpedunculated colorectal lesions: a prospective two-center study. Am J Gastroenterol. 2014; 109(2):183-9.

6. Robertson DJ, Lieberman DA, Winawer SJ, Ahnen DJ, Baron JA, Schatzkin A, et al. Colorectal cancers soon after colonoscopy: a pooled multicohort analysis. Gut. 2014;63(6):949-56.

7. Tanaka S, Kashida H, Saito Y, Yahagi N, Yamano H, Saito S, et al. JGES guidelines for colorectal endoscopic submucosal dissection/endoscopic mucosal resection. Dig Endosc. 2015;27(4):417-34.

8. Hong SN, Byeon JS, Lee BI, Yang DH, Kim J, Cho KB, et al. Prediction model and risk score for perforation in patients undergoing colorectal endoscopic submucosal dissection. Gastrointest Endosc. 2016;84(1):98-108.

9. Sato $K$, Ito $S$, Kitagawa $T$, Kato M, Tominaga K, Suzuki T, et al. Factors affecting the technical difficulty and clinical outcome of endoscopic submucosal dissection for colorectal tumors. Surg Endosc. 2014;28(10): 2959-65.

10. Schurr MO, Buess G, Raestrup H, Arezzo A, Buerkert A, Schell C, et al. Full thickness resection device (FTRD) for endoluminal removal of large bowel tumours: development of the instrument and related experimental studies. Minim Invasive Ther Allied Technol. 2001;10(6):301-9.

11. Schurr MO, Baur FE, Krautwald M, Fehlker M, Wehrmann M, Gottwald T, et al. Endoscopic full-thickness resection and clip defect closure in the colon with the new FTRD system: experimental study. Surg Endosc. 2015;29(8): 2434-41.

12. Sarker S, Gutierrez JP, Council L, Brazelton JD, Kyanam Kabir Baig KR, Monkemuller K. Over-the-scope clip-assisted method for resection of fullthickness submucosal lesions of the gastrointestinal tract. Endoscopy. 2014; 46(9):758-61.

13. Fahndrich M, Sandmann M. Endoscopic full-thickness resection for gastrointestinal lesions using the over-the-scope clip system: a case series. Endoscopy. 2015;47(1):76-9.

14. Al-Bawardy B, Rajan E, Wong Kee Song LM. Over-the-scope clip-assisted endoscopic full-thickness resection of epithelial and subepithelial GI lesions. Gastrointest Endosc. 2017;85(5):1087-92.

15. Schmidt A, Beyna T, Schumacher B, Meining A, Richter-Schrag HJ, Messmann $\mathrm{H}$, et al. Colonoscopic full-thickness resection using an over-thescope device: a prospective multicentre study in various indications. Gut. 2018;67(7):1280-9.

16. Vitali F, Naegel A, Siebler J, Neurath MF, Rath T. Endoscopic full-thickness resection with an over-the-scope clip device (FTRD) in the colorectum: results from a university tertiary referral center. Endosc Int Open. 2018;6(1): E98-e103.
17. Richter-Schrag HJ, Walker C, Thimme R, Fischer A. Full thickness resection device (FTRD). Experience and outcome for benign neoplasms of the rectum and colon. Chirurg. 2016;87(4):316-25.

18. Valli PV, Mertens J, Bauerfeind P. Safe and successful resection of difficult Gl lesions using a novel single-step full-thickness resection device (FTRD(R)). Surg Endosc. 2018;32(1):289-99.

19. Andrisani G, Soriani P, Manno M, Pizzicannella M, Pugliese F, Mutignani M, et al. Colo-rectal endoscopic full-thickness resection (EFTR) with the overthe-scope device $(F T R D((R)))$ : a multicenter Italian experience. Dig Liver Dis. 2019:51(3):375-81.

20. Hayashi N, Tanaka S, Hewett DG, Kaltenbach TR, Sano Y, Ponchon T, et al. Endoscopic prediction of deep submucosal invasive carcinoma: validation of the narrow-band imaging international colorectal endoscopic (NICE) classification. Gastrointest Endosc. 2013;78(4):625-32.

21. Berr F, Wagner A, Kiesslich T, Friesenbichler P, Neureiter D. Untutored learning curve to establish endoscopic submucosal dissection on competence level. Digestion. 2014;89(3):184-93.

\section{Publisher's Note}

Springer Nature remains neutral with regard to jurisdictional claims in published maps and institutional affiliations.
Ready to submit your research? Choose BMC and benefit from:

- fast, convenient online submission

- thorough peer review by experienced researchers in your field

- rapid publication on acceptance

- support for research data, including large and complex data types

- gold Open Access which fosters wider collaboration and increased citations

- maximum visibility for your research: over $100 \mathrm{M}$ website views per year

At BMC, research is always in progress.

Learn more biomedcentral.com/submissions 